\title{
Diagnosis, treatment and prevention of ankle sprains: an evidence-based clinical guideline
}

Gino M Kerkhoffs, ${ }^{1}$ Michel van den Bekerom, ${ }^{2}$ Leon A M Elders, ${ }^{3}$ Peter A van Beek, ${ }^{4}$ Wim A M Hullegie, ${ }^{5}$ Guus M F M Bloemers, ${ }^{6}$ Elly M de Heus, ${ }^{7}$ Masja C M Loogman, ${ }^{8}$ Kitty C J G M Rosenbrand, ${ }^{9}$ Ton Kuipers, ${ }^{10}$ J W A P Hoogstraten, ${ }^{11}$ Rienk Dekker, ${ }^{12}$ Henk-Jan ten Duis, ${ }^{13} \mathrm{C}$ Niek van Dijk, ${ }^{14}$ Maurits W van Tulder, ${ }^{15}$ Philip J van der Wees, ${ }^{16}$ Rob A de Bie ${ }^{16}$

\begin{abstract}
Ankle injuries are a huge medical and socioeconomic problem. Many people have a traumatic injury of the ankle, most of which are a result of sports. Total costs of treatment and work absenteeism due to ankle injuries are high. The prevention of recurrences can result in large savings on medical costs. A multidisciplinary clinical practice guideline was developed with the aim to prevent further health impairment of patients with acute lateral ankle ligament injuries by giving recommendations with respect to improved diagnostic and therapeutic opportunities. The recommendations are based on evidence from published scientific research, which was extensively discussed by the guideline committee. This clinical guideline is helpful for healthcare providers who are involved in the management of patients with ankle injuries.
\end{abstract}

\section{INTRODUCTION}

In the Netherlands, about 520000 persons annually have a traumatic injury of the ankle of which about 200000 are a result of sports. ${ }^{1}$ Around half of the injuries receive medical treatment and $40 \%$ results in chronic instability. ${ }^{1}$ The average work absenteeism of patients with a

For numbered affiliations see end of article

Correspondence to MPJ van den Bekerom, Spaarnepoort 1, 2130 AT Hoofddorp, the Netherlands; bekerom@gmail.com or to GMMJ Kerkhoffs,

Meibergdreef 9, 1100 DD Amsterdam;

G.M.Kerkhoffs@amc.uva.nl

GMK and MvdB contributed equally to the manuscript. functional-treated ligament rupture is two and a half weeks and after six weeks, 90\% has returned to work. ${ }^{1}$ Of the patients who perform sports, around 60-90\% resume sports after 12 weeks at the same level as before the trauma. ${ }^{1}$ About one-third of the total costs due to sport injuries are caused by ankle injuries. ${ }^{1}$ The prevention of recurrence can result in substantial cost savings. An example from a Dutch study showed mean total costs of one ankle sprain to be about E360. ${ }^{2}$ With the abovementioned 520000 persons with an ankle sprain, Dutch annual sports-related ankle sprain costs can roughly be estimated at E187.2 million. Productivity loss due to absence from paid and unpaid work was responsible for up to $80 \%$ of these costs. ${ }^{2}$ ${ }^{3}$ Despite the growing body of evidence, international debate shows controversy for best treatment strategies after ankle injuries. ${ }^{45}$ Till date, no international guidelines have been published for the management of acute ankle injuries (International Guideline Library (www.g-i-n.net); US National Guideline Clearinghouse (www. guideline.gov).

Recently, in the Netherlands, a clinical guideline for acute lateral ankle ligament injury was developed under the auspices of the Royal Dutch Society for Physical Therapy in cooperation with many medical professional associations and patients, following the AGREE criteria. ${ }^{6}$ Specific goal of this clinical guideline is the prevention of further health impairment of patients (ie, recurrences) by providing recommendations for improved diagnostic and therapeutic opportunities. Other goals are to obtain uniformity of diagnostics, treatment and guidance of doctors and physical therapists and other involved professional groups and to define the framework within which the multidisciplinary care of patients with ankle injuries has to take place. This guideline will also contribute to improved communication between healthcare professionals.

\section{Target group}

The guideline is meant for all care providers who are involved in the treatment and guidance of patients with ankle injuries: family physicians, physical therapists, orthopaedic surgeons, trauma surgeons, rehabilitation physicians, radiologists, occupational physicians, sports physicians and professionals involved in sport massage.

\section{MATERIALS AND METHODS}

The recommendations set in this guideline are, if available, based on evidence from published scientific research. Relevant articles were searched in the Cochrane Library, Medline and Embase. The full search strategy is available upon request. The language was limited to Dutch, English, German, French, Danish, Norwegian and Swedish. In search for additional information, all reference lists of the included articles were checked manually. Articles published between January 1996 and March 2009 were enclosed. The quality of included articles was assessed by epidemiologists on the basis of 'evidence-based guideline development' assessment forms and classified in various levels in order of probative and scientific value (tables 1 and 2). The results based on the evidence from literature are presented in categories with levels of evidence of the conclusions included. In formulating the final recommendations, the guideline committee also took other aspects into account, such as potential harm of the interventions, patients' perspective, costs and organisational aspects. If the guideline committee decided that based on current evidence a positive recommendation was not opportune, this was stated as well. So, recommendations were evidence-based and consensus-based. Below, the evidence and discussion among the committee members are summarised, and the final recommendations presented in italics.

\section{RESULTS}

\section{Predisposing factors}

Intrinsic and extrinsic risk factors may increase the chance of acute lateral ankle ligament injury or in short lateral ankle injury (LAI). In order to unravel the 
Table 1 Classification of methodological quality of individual studies

\begin{tabular}{|c|c|c|c|}
\hline & Intervention & Diagnostic accuracy of research & Damage or side effects, aetiology, prognosis* \\
\hline A2 & $\begin{array}{l}\text { Randomised double-blind comparative } \\
\text { clinical research of good quality of } \\
\text { sufficient size }\end{array}$ & $\begin{array}{l}\text { Research relative to a reference test (a 'golden standard') with } \\
\text { predefined cut-off points and independent assessment of the } \\
\text { results of a test and golden standard, on a sufficiently large } \\
\text { series of consecutive patients who all have had the index } \\
\text { and reference test }\end{array}$ & $\begin{array}{l}\text { Prospective cohort study of sufficient size and } \\
\text { follow-up, at which adequately controlled for } \\
\text { 'confounding' and selective follow-up sufficient is } \\
\text { excluded. }\end{array}$ \\
\hline B & $\begin{array}{l}\text { Comparative research, but not with } \\
\text { all the features as mentioned under A2 } \\
\text { (this includes patient-control research, } \\
\text { cohort study) }\end{array}$ & $\begin{array}{l}\text { Research relative to a reference test, but not with all the } \\
\text { attributes that are listed under A2 }\end{array}$ & $\begin{array}{l}\text { Prospective cohort study, but not with all the } \\
\text { features as mentioned under } \mathrm{A} 2 \text { or retrospective } \\
\text { cohort study or patient-monitoring research }\end{array}$ \\
\hline C & Not comparative research & & \\
\hline D & Opinion of experts & & \\
\hline
\end{tabular}

*This classification only applies to situations in which due to ethical or other reasons controlled trials are not possible to perform. If these are possible, then the classification applies to interventions.

importance of extrinsic risk factors for athletes, a specific search was performed for risk factors relating to the type of surface on which to play and the player position during the game.

\section{Intrinsic risk factors}

Four risk factors are important: strength, propriocepsis, range of motion and balance of patients older than 15 years with a primary or recurrent lateral ankle ligament injury. The definition of LAI, ADL (activities of daily living) in the literature varied widely. ${ }^{7}$ There are indications that limited dorsal flexion ${ }^{8}$ and reduced propriocepsis $^{9}$ lead to an increased risk of sustaining an LAI (Level 3). It is plausible that an ankle distortion in the past ${ }^{10} 11$ and reduced balance predispose for LAI, ADL. ${ }^{912-17}$

\section{Extrinsic risk factors}

Among a group of 2016000 players of all kind of sports, 14098 patients with LAI were selected of whom the medical files were available. The highest incidence of ankle injuries was reported due to playing aero ball, in wall climbing, indoor volleyball, rock climbing, basketball and field sports. ${ }^{18}$ The incidence is dependent on the type of sport, the total number of players and whether a competition is involved (Level 2). ${ }^{18}$ Among soccer players, playing on artificial grass seems to slightly increase the incidence (Level 2) $)^{19} 20$ and defenders and attackers have a higher risk due to contact with opponents (Level 2). ${ }^{21-23}$ In volleyball players, landing after a jump seems to be the most important risk factor (Level 2). ${ }^{24} 25$

Based on current research data, no recommendations concerning predisposing factors for LAI, ADL can be made for daily practice.

\section{Prognostic factors}

Research of high quality concerning the relationship between prognostic factors and LAI is lacking. The natural course is good; most patients with LAI show complete recovery over time. Pain decreases rapidly in the first 2 weeks after an ankle distortion (Level 1). ${ }^{26}$ After 1 year, 5\% to $33 \%$ of the patients with LAI still have pain and have complaints of instability (Level 1$)^{26}$ and $3 \%$ to $34 \%$ has a recurrent distortion (Level 1). ${ }^{26}$ Sports performed at high level is possibly an unfavourable prognostic factor for the development of residual complaints (Level 3). ${ }^{27}$ Increased ligament laxity after an ankle distortion might also be an unfavourable prognostic factor for the development of chronic instability (Level 3). ${ }^{28}$

Based on current research data, no recommendations concerning neither prognostic factors nor natural course of LAI can be made for daily practice.

\section{Ottawa ankle rules}

In LAI, ADL, the existence of a fracture is the main red flag. The ability to walk again within $48 \mathrm{~h}$ after trauma is an auspicious sign and indicates a good prognosis. ${ }^{29}$ The Ottawa Ankle Rules have been developed to rule out fractures after acute ankle injuries. ${ }^{30}$ Most patients who visit the emergency room are examined using radiographs to rule out fractures despite the fact that the prevalence of ankle fractures is less than $15 \% .^{30}$ The Ottawa Ankle Rules consists of a questionnaire and research protocol for examination of ankle and foot. X-ray diagnostics is only indicated in case of pain in the malleoli or middle foot, combined with one of the following findings: palpation pain on the dorsal side of one or both of the malleoli, palpation pain at the bases of the metatarsal bone $\mathrm{V}$, palpation pain of the navicular bone and finally if the patient is unable to walk at least four steps. Among 73 studies concerning Ottawa Ankle Rules, four review studies of importance were
Table 2 Level of conclusions

\section{Conclusions based on}

1 Research of level $\mathrm{A} 1$ or at least two examinations of level A2 performed independently of each other, with consistent results

2 One examination of level A2 or at least two examinations of level B, performed independently of each other

3 One examination of level $B$ or $C$

4 Opinion of experts

identified. ${ }^{30-33}$ Ottawa Ankle Rules seems to be an accurate tool to exclude fractures in the emergency room within the first week after acute ankle injury (Level 1). ${ }^{30}$ This finding was acknowledged by results of research from the Netherlands (Level 2). ${ }^{34}$ Studies about the use of Ottawa Ankle Rules outside the hospital are missing. (Level 4) It seems plausible that the predictive value of the Ottawa Ankle Rules when used in a general practice is reduced due to the lower incidence of serious ankle injuries or ruptures of ligaments of the ankle. ${ }^{35} 36$

The use of the Ottawa Ankle Rules is strongly recommended in the emergency room of hospitals and in general practice in order to exclude fractures.

In the training of healthcare professionals, sufficient attention should be paid to proper application of the Ottawa Ankle Rules.

\section{Diagnostics}

If a haematoma is present accompanied by local pressure pain at palpation or a positive anterior drawer test is present or both, it is most likely that a (partial) lateral ankle ligament rupture exists. Delayed physical diagnostic examination (4 to 5 days) gives a better diagnostic result than research within 48 h. The sensitivity of delayed physical examination is $96 \%$ and the specificity $84 \%$ (Level 2). ${ }^{35}$ Knowledge about the 
Table 3* Effects in favour of functional treatment compared with immobilisation in the event of acute ankle injury ${ }^{46}$

\begin{tabular}{|c|c|}
\hline \multicolumn{2}{|l|}{ Short-term (0 to 6 weeks) } \\
\hline Return to work & 2 RCTs; $n=150 ; \operatorname{RR} 5.75$ (95\% Cl 1.01 to 32.71$)$ \\
\hline Swelling & 3 RCTs; $n=260 ;$ RR 1.74 (95\% Cl 1.17 to 2.59 ) \\
\hline \multicolumn{2}{|l|}{ Medium term ( 6 weeks-1 year) } \\
\hline Patient satisfaction & 2 RCTs; $n=123 ;$ RR 4.25 (95\% Cl 1.12 to 16.09 ) \\
\hline \multicolumn{2}{|l|}{ Long term (>1 year) } \\
\hline Return to sports & 5 RCTs; $n=360 ; \mathrm{RR} 1.86$ (95\% Cl 1.22 to 2.86 ) \\
\hline Resuming sport activity (number of days) & 3 RCTs $\mathrm{n}=195 ; \mathrm{MD} 4.88$ (95\% $\mathrm{Cl} 1.50$ to 8.25$)$ \\
\hline Return to work (number of days) & 6 RCTs $n=604 ;$ MD 8.23 (95\% Cl: 6.31 to 10.16$)$ \\
\hline
\end{tabular}

*The effects per comparison are in favour of the former interventions.

$M D$, mean difference; RCT, randomised controlled trials.

Table 4 Results* of functional treatments for acute ankle injury ${ }^{48}$

Short-term (0-6 weeks)

Swelling

Semirigid brace vs lace-up brace

Elastic bandage vs lace-up brace

Tape vs lace-up brace

Return to work (number of days)

Elastic bandage vs semirigid brace

Resuming sport activity

Elastic bandage vs semirigid brace (subjective) Instability

Semirigid brace vs elastic bandage

Complications (ie, skin irritations)

Elastic bandage vs tape

$1 \mathrm{RCT} ; \mathrm{n}=122: \mathrm{RR} 4.19,95 \% \mathrm{Cl} 1.26$ to 13.98

$1 \mathrm{RCT} ; \mathrm{n}=122: \mathrm{RR} 5.48,95 \% \mathrm{Cl} 1.69$ to 17.76

$1 \mathrm{RCT} ; \mathrm{n}=119 ; \mathrm{RR} 4.07$ (95\% Cl 1.21 to 13.68)

2 RCTs; $n=157:$ WMD $4.24,95 \%$ Cl 2.42 to 6.06

$1 \mathrm{RCT} ; \mathrm{n}=84: \mathrm{RR} 9.60,95 \% \mathrm{Cl} 6.34$ to 12.86

$1 \mathrm{RCT} ; \mathrm{n}=104: \mathrm{RR} 8.00,95 \% \mathrm{Cl} 1.03$ to 62.07

$2 \mathrm{RCT} ; \mathrm{n}=208: \mathrm{RR} 0.11,95 \% \mathrm{Cl} 0.01$ to 0.86

*The effects per comparison are in favour of the former interventions.

$\mathrm{RCT}$, randomised controlled trials; WMD, weighted mean difference.

use of ultrasound and MRI examination and their diagnostic performance is hampered by lack of research (Level 4). Arthrography within $48 \mathrm{~h}$ after an inversion trauma is highly sensitive but not recommended (Level 2). . $^{36-39}$

For a solid diagnosis of an ankle ligament rupture, patients must be re-examined 4 to 5 days after the trauma.

If a haematoma develops and patients experience local pressure pain at palpation or a positive anterior drawer test is present or both, it is very likely that a ligament rupture exists.

\section{Treatment \\ The use of ice and compression in the inflam- matory phase after acute ankle injuries}

In the event of an acute ankle injury, the effect of ice (cryotherapy) is unclear. ${ }^{40}$ Ice combined with exercise therapy has a positive effect on the swelling in comparison with heat application. ${ }^{41}$ The effectiveness of compression shows conflicting results (Level 2). ${ }^{42-44}$ Intermittent application of ice has a significant effect on shortterm pain reduction (difference $\pm 1 \mathrm{~cm}$ in a visual analogue scale) in comparison with standard application of ice. There are no indications that the use of ice only is effective to reduce swelling, increase function and reduce pain at rest in the event of an acute ankle injury (Level 2). ${ }^{40} 45$

The use of ice and compression, in combination with rest and elevation, is an important aspect of treatment in the acute phase of LAI.

\section{Immobilisation after acute ankle injuries}

Research from a systematic review (21 randomised controlled trials (RCTs), $\mathrm{N}=2184$ ) showed that a longer period of immobilisation in a lower leg cast (minimum of 4 weeks) is less effective compared with different functional treatments (Level 2) (see table 3). ${ }^{46}$ However, due to great variation in methodological quality, the conclusions from this review should be interpreted with some caution (Level 2). ${ }^{46}$ Recent evidence from 1 RCT $(\mathrm{N}=584)$ states that a short period of plaster immobilisation (10 days) or rigid support for reduction of pain and swelling can still be considered of help in the treatment of LAI. ${ }^{47}$

A short period of plaster immobilisation or similar rigid support facilitating a rapid decrease of pain and swelling can be helpful in the acute phase of the treatment of LAI.

Functional treatment for 4 to 6 weeks is preferable to immobilisation in a cast.
Optimal functional treatment after acute ankle injuries

A systematic review (9 RCTs, N=892) investigated the effect of different functional treatments for acute ankle injuries such as exercise therapy and immobilisation by means of tape or brace (Level 2) (see table 4). ${ }^{48}$ Elastic bandages gave fewer complications than tape, but was associated with a delayed return to work and sports. Instability was reported more frequently compared with a semirigid ankle brace. A lace-up brace or a semirigid brace seems preferable to the use of an elastic bandage (Level 2). ${ }^{48}$ However, in this review, insufficient data were present to draw definite conclusions from literature.

A lace-up brace or a semirigid brace is preferable and recommended.

Based on consensus in the committee in (professional) sports also the use of tape can be considered.

Exercise therapy after acute inversion injury Besides three recent RCTs, ${ }^{49-51}$ four systematic reviews of sufficient quality were found on this subject. ${ }^{52-55}$ Exercise therapy seems to prevent a recurrence in patients with LAI (2 RCTs, $n=130$ ) ( $R R$ $0.37 ; 95 \% 0.18$ to 0.74 ) on the long term (8 to 12 months) (Level 2). ${ }^{54}$ Exercise therapy seems to have no (significant) effect on balance on the medium term ( 6 to 9 months) (2 RCTs, n=78) (SMD 0.38; 95\% -0.15 to 0.91 ) (Level 2). ${ }^{54}$

Exercise therapy should be used in the treatment of LAI.

Exercise therapy can also be applied at home.

\section{Manual mobilisation after acute ankle injuries}

Three systematic reviews were identified, ${ }^{52-54}$ the most recent review included all trials from the other two reviews. ${ }^{54}$ There are limited positive (very) short-term effects (dorsalflexion, ROM, propriocepsis) in favour of manual mobilisation of the ankle (6 RCTs, N=224) (Level 2). ${ }^{52-54}$ However, the clinical relevance of these findings is limited since the effects had disappeared 2 weeks after injury.

Manual mobilisation of the ankle has limited added value and is not recommended.

\section{Other therapies after acute ankle injuries}

In literature, no effect was found of ultrasound, laser therapy ${ }^{56}$ and electrotherapy in the treatment of acute ankle injuries ${ }^{57-59}$ (Level 1). Short-wave therapy also seems ineffective (Level 2). ${ }^{60-64}$

Ultrasound, laser and electrotherapy have no added value and are not recommended. 
Table 5 Checklist. Essential information for healthcare professionals during referral of patient with $L A I, A D L$

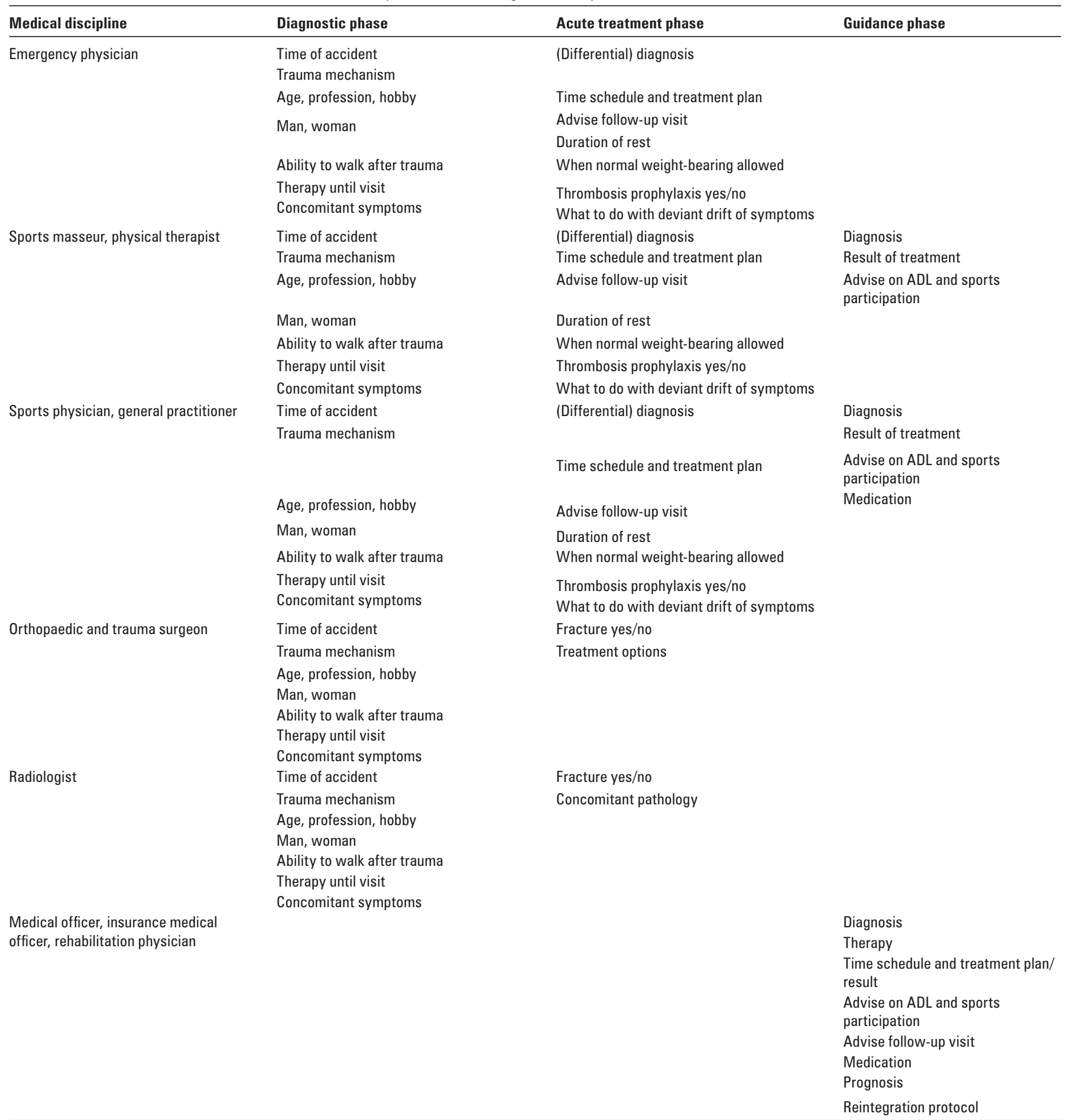

$A D L$, activities of daily living; $L A I$, lateral ankle injury.

\section{Surgical therapy after acute lateral ankle ligament injury}

A systematic review concluded that there was some limited evidence for longer recovery times, and higher incidences of ankle stiffness, impaired ankle mobility and complications after surgical treatment (20 RCTs, N=2562) (Level 2). ${ }^{65}$ However, final conclusion from this review was that there are insufficient high-quality RCTs available to give a final judgement on the effectiveness of surgery compared with conservative treatment in LAI (20 RCTs, $\mathrm{N}=2562$ ) (Level 2). ${ }^{65}$

Functional treatment is preferred over surgical therapy.

Based on consensus in the committee, it is recommended that in (top-professional) sports surgical treatment can be considered on an individual basis.

\section{Communication between healthcare professionals}

In order to be able to effectively refine communication between healthcare professionals during referral of patients with LAI, the essential information has been inventoried by consensus of the guideline committee. A distinction was made between the diagnostic phase, the treatment phase and the guidance phase. The 
Table 6 Return to work ${ }^{75}$

\begin{tabular}{|c|c|c|c|}
\hline Degree of inversion injury & Return to light work & Restrictions & Full return to former work \\
\hline Distortion & 2 Weeks & $\begin{array}{l}\text { Mostly sitting work } \\
\text { Not exceeding } 10 \mathrm{~kg} \text { of lifting } \\
\text { Limit standing and walking } \\
\text { position on uneven surfaces }\end{array}$ & $\begin{array}{l}3-4 \text { Weeks depending on } \\
\text { the task requirements }\end{array}$ \\
\hline $\begin{array}{l}\text { Partial or total rupture of } \\
\text { ligaments }\end{array}$ & 3-6 Weeks & $\begin{array}{l}\text { Mostly sitting work } \\
\text { Not exceeding } 10 \mathrm{~kg} \text { of lifting } \\
\text { Limit standing and walking } \\
\text { position on uneven surfaces }\end{array}$ & $\begin{array}{l}6-8 \text { Weeks depending on } \\
\text { the task requirements and } \\
\text { the result of physiotherapy }\end{array}$ \\
\hline
\end{tabular}

different disciplines involved in communication are emergency physician, sports masseur and physical therapist, sports physician and general practitioner, orthopaedic and trauma surgeon, radiologist, medical officer for occupational medicine and rehabilitation physicians.

Communication between healthcare professionals involved in the treatment of LAI can be short and effective, if the referring professional takes care to exactly provide the correct information.

The use of the information checklist will refine communication between healthcare professionals involved in the treatment of patients with LAI (table 5) and is recommended.

\section{Prevention \\ Exercise therapy}

Besides one recent RCT, 66 one systematic review reports that exercise therapy shows no significant beneficial effect on balance on midterm (6 to 9 months) follow-up in patients with LAI (Level2) (2 RCTs, N=1577) (SMD 0.38; $95 \%-0.15$ to 0.91). Also training coordination and balance have no effect on the prevention of primary (first) inversion injuries of the ankle in athletes (Level 2). ${ }^{11}$ 6768 However, the results of two RCTs and two systematic reviews suggest that training coordination and balance does prevent recurrence of ankle injuries in athletes up to 12 months postinjury (Level 2). ${ }^{135469}$

After LAI, it is recommended to train balance and coordination, especially among athletes, starting within 12 months after the occurrence of the injury.

Exercise therapy should be included as much as possible into regular training activities or at home to prevent recurrences or both.

\section{Tape or brace to prevent inversion injury}

The results from three systematic reviews suggest that the use of a brace and tape reduces the risk of recurrent inversion injuries in those who are active in sports (Level 2) (5 RCTs, $\mathrm{N}=2858$ ) (RR 0.53, $95 \%$ CI 0.40 to 0.69). ${ }^{17071}$ However, it is unclear whether a brace is more effective than a tape (Level 2). ${ }^{148} 72$ The preference for the choice of a brace or a tape depends on the individual situation. Due to considerations about practical usability and evaluation of costs, a brace is initially preferable to a tape.

It is recommended to use a brace or a tape to prevent a relapse.

The use of a brace or a tape is a personal choice. On the basis of practical usability and evaluation of costs, a brace is initially the preferable means of support.

It is recommended to phase out the use of brace or tape in time.

\section{Preventive effect of footwear}

Two systematic reviews (3 RCTs, N=3410) found no differences in protective effect of either high-fitted or low-fitted workor sport shoes to avoid (recurrent) LAI (Level 2). ${ }^{170} 73$

No recommendations can be made concerning the type of shoes to prevent recurrence of ankle ligament injury.

\section{Resuming work}

One systematic review (2 RCTs, N=159) concluded that workers who use a semirigid ankle brace seem to resume work faster than workers who use an elastic bandage (Level 2) (4.2 days; 95\% CI 2.4 to 6.1 days). ${ }^{48}$ Discrimination between the degrees of injury can support the initial treatment and prognosis in relation to return to work (Level 4). ${ }^{74}$ A resumption of work strategy and a return to work schedule, which takes into account the task requirements, can contribute to optimise reintegration towards work (Level 3) (table 6). ${ }^{7576}$

Workers with LAI should preferably be treated with a brace to speed up work resumption.

\section{Sport resumption}

In the Netherlands about 3.5 million athletes annually have a sports injury, of which 1.4 million seek medical treatment. Sixteen per cent of all sports injuries (570 000) are ankle injuries and 26000 athletes with ankle injuries are treated in the emergency room of a hospital annually. ${ }^{77}$ Distortion of the ankle as well as a lateral ankle ligament rupture can lead to a disturbance in propriocepsis through which a functional instability may arise. This disturbance seems to be hosted in the central nervous system above the level of the spinal reflex (Level 2). ${ }^{217879}$ A delayed response time of the peroneal muscle may occur as a result of (traction) injury of the peroneal nerve. It seems that motor-unit insufficiencies after a distortion are less long lasting than those after LAI (Level 2). ${ }^{80-83}$ Another effect may be strength reduction of extensor muscles (used in eversion) and other muscles around the ankle. These muscles may benefit significantly from a strength training programme (Level 2). ${ }^{84-88}$

Rehabilitation of athletes after LAI must be the result of a variety of exercises in which propriocepsis, strength, coordination and function of the extremity are maintained.

\section{DISCUSSION}

A clinical guideline for acute lateral ankle ligament injury was developed under the auspices of the Royal Dutch Society for Physical Therapy by a group including content experts for all specialties involved, methodologists experienced in developing guidelines, health professionals involved in the healthcare process and patients. The idea behind guidelines is to provide a considered, unbiased, evidence-based, accessible, transparent and easy-to-use summary of the implications of current health knowledge for practice, which, if used, should improve the quality of care. ${ }^{89}$

Guideline development is essential in improving 'evidence-based practice', but development is a complex process. Even good guidelines have tended to lie on shelves gathering dust because of the difficulty of distinguishing them from bad ones. At the start of this project, a limited set of relevant questions from daily clinical practice was selected to be answered by the guideline. Consequently, a possible weakness of the guideline is identified in the fact that there are still some issues open for debate. Another possible flaw is that even though the recommendations in this guideline are based on best evidence from literature, ultimately converting the evidence into recommendations was a consensus process among the committee members, leaving room for bias. However, having all relevant health professionals involved in the guideline committee has probably limited this bias.

A definite strength of the current guideline is that essential referral data are now 


\section{What is already known?}

- The incidence and trauma mechanism of lateral ankle injury (LAI) are known.

- A variety of therapeutic interventions is available for restoring stability and diminishing pain and swelling in patients with LAI.

- There is still no uniform treatment of LAI despite the large number of clinical trials.

\section{What this study adds}

- A systematic, evidence-based guideline of the prevention, predictors, diagnosis, operative and conservative treatment and prognosis of lateral ankle injury (LAI) was lacking.

- This guideline incorporates a perspective from several healthcare professionals and patients with the clinicalevidencetoformulateaguideline concerning LAI.

available for refinement of communication between healthcare professionals, in the Netherlands and all over the world.

Future research is warranted to investigate a number of alternative prophylactic interventions, their cost-effectiveness and general applicability. Additionally, future research requires the design of high-quality randomised controlled trials of the best available conservative treatment for welldefined injuries, with special focus on the benefit of a short period of immobilisation in the treatment of LAI.

Contributors This manuscript was written by the first three authors based on the national guideline. The other authors were all members of the guideline committee. This manuscript was read and approved by all authors.

Acknowledgements Royal Dutch Society for Physical Therapy KNGF Organisation; Dutch Institute for Healthcare Improvement CBO; Collaborating associations/institutes; Royal Dutch Society for Physical Therapy; Dutch Association of General Healthcare NHG; Dutch Orthopedic Society NOV; Dutch Society of Rehabilitation NVR; Dutch Trauma Society NVT

Dutch Radiological Society NVR; Netherlands Society of Occupational Medicine NVAB; Dutch Society for Physical Therapy in Sports NVFS; Dutch Society Sports Physicians VSG; Dutch Association of Sports Massage NGS; Association of Orthopedic Patients SPO.

Funding The development of this guideline was financially supported by the Netherlands organisation for health research and development (ZonMw) within the framework of the programme 'Management of Knowledge, Quality Curative Care'. Neither they nor a member of their immediate families received payments or other benefits or a commitment or agreement to provide such benefits from a commercial entity. No commercial entity paid or directed, or agreed to pay or direct, any benefits to any research fund, foundation, division, centre, clinical practice or other charitable or non-profit organisation with which the authors, or a member of their immediate families, are affiliated or associated. Dutch Ministry of Health, Welfare and Sport

\section{Competing interests None.}

Provenance and peer review Not commissioned; externally peer reviewed.

Received 12 August 2011

Accepted 1 February 2012

Published Online First 20 April 2012

Br J Sports Med 2012;46:859-865.

doi:10.1136/bjsports-2011-090490

Author affiliations ${ }^{1}$ Gino MMJ Kerkhoffs, Dutch Orthopaedic Society, Academic Medical Center, Amsterdam, the Netherlands

2Michel P van den Bekerom, Spaarne hospital, Hoofddorp, the Netherlands

${ }^{3}$ Leo AM Elders, Netherlands Society of Occupational Medicine, Department of Allergology/lnternal medicine, Erasmus Medical Center, Rotterdam, the Netherlands

${ }^{4}$ Peter A van Beek, Dutch Society Sports Physicians, Bilthoven, the Netherlands

${ }^{5}$ Wim AM Hullegie, Dutch Society for Physical Therapy in Sports, Royal Dutch Society for Physical Therapy,

Fysiogym, Enschede, the Netherlands

${ }^{6}$ Guus MFM Bloemers, Dutch Association of Sports

Massage, Arnhem, the Netherlands

${ }^{7}$ Elly M de Heus, Association of Orthopedic Patients, Age Concern, Apeldoorn, the Netherlands

${ }^{8}$ Masja CM Loogman, Dutch Association of General Healthcare, Utrecht, the Netherlands

${ }^{9}$ Kitty CJGM Rosenbrand, Dutch Institute for Healthcare Improvement, Utrecht, the Netherlands

${ }^{10}$ Ton Kuipers, Dutch Institute for Healthcare Improvement, Utrecht, the Netherlands

${ }^{11}$ Jos WAP van Hoogstraten, Dutch Radiological

Society, Deventer hospitals, Deventer, the

Netherlands

${ }^{12}$ Rienk Dekker, Dutch Society of Rehabilitation, University Medical Center, Groningen, the Netherlands ${ }^{13}$ Henk Jan ten Duis, Professor in Traumatology, Dutch Trauma Society, UMCG, Groningen, the Netherlands

${ }^{14} \mathrm{C}$ Niek van Dijk, Professor in Orthopedic Surgery,

Dutch Orthopedic Society, Academic Medical Center, Amsterdam, the Netherlands

${ }^{15}$ Maurits W van Tulder, Professor of Health Technology Assessment, EMGO, Amsterdam, the Netherlands

${ }^{16}$ Philip J van der Wees, UM, Maastricht, the Netherlands

${ }^{16}$ Rob A de Bie, UM, Maastricht, the Netherlands

\section{REFERENCES}

1. Verhagen EA, van Mechelen W, de Vente W. The effect of preventive measures on the incidence of ankle sprains. Clin J Sport Med 2000;10:291-6.

2. Verhagen EA, van Tulder $\mathrm{M}$, van der Beek AJ, et al. An economic evaluation of a proprioceptive balance board training programme for the prevention of ankle sprains in volleyball. Br J Sports Med 2005;39:111-15.

3. Hupperets MD, Verhagen EA, van Mechelen W. Effect of unsupervised home based proprioceptive training on recurrences of ankle sprain: randomised controlled trial. BMJ 2009;339:b2684.

4. Hertel J. Immobilisation for acute severe ankle sprain. Lancet 2009:373:524-6.

5. Kerkhoffs GM, van den Bekerom MP, Struijs PA et al. 10-day below-knee cast for management of severe ankle sprains. Lancet 2009;373:1601; author reply 1602-3.

6. Cluzeau FA, Burgers JS, Brouwers MC, et al Development and validation of an international appraisal instrument for assessing the quality of clinical practice guidelines: the AGREE project. Qual Saf Health Care 2003:12:18-23.
7. de Noronha M, Refshauge KM, Herbert RD, et al. Do voluntary strength, proprioception, range of motion, or postural sway predict occurrence of lateral ankle sprain? Br J Sports Med 2006;40:824-8; discussion 828

8. Pope R, Herbert R, Kirwan J. Effects of ankle dorsiflexion range and pre-exercise calf muscle stretching on injury risk in Army recruits. Aust $J$ Physiother 1998:44:165-72.

9. Willems TM, Witvrouw E, Delbaere K, et al. Intrinsic risk factors for inversion ankle sprains in male subjects: a prospective study. Am J Sports Med 2005;33:415-23.

10. McHugh MP, Tyler TF, Tetro DT, et al. Risk factors for noncontact ankle sprains in high school athletes: the role of hip strength and balance ability. Am J Sports Med 2006:34:464-70.

11. Verhagen $\mathbf{E}$, van $\operatorname{der}$ Beek A, Twisk J, et al. The effect of a proprioceptive balance board training program for the prevention of ankle sprains: a prospective controlled trial. Am J Sports Med 2004;32:1385-93.

12. Hrysomallis C, McLaughlin P, Goodman C. Balance and injury in elite Australian footballers. Int J Sports Med 2007;28:844-7

13. McGuine TA, Keene JS. The effect of a balance training program on the risk of ankle sprains in high school athletes. Am J Sports Med 2006;34:1103-11.

14. Trojian TH, McKeag DB. Single leg balance test to identify risk of ankle sprains. Br J Sports Med 2006;40:610-13; discussion 613.

15. Tropp H, Ekstrand J, Gillquist J. Stabilometry in functional instability of the ankle and its value in predicting injury. Med Sci Sports Exerc 1984:16:64-6.

16. Wang HK, Chen $\mathrm{CH}$, Shiang TY, et al. Risk-factor analysis of high school basketball-player ankle injuries: a prospective controlled cohort study evaluating postural sway, ankle strength, and flexibility. Arch Phys Med Rehabil 2006;87:821-5.

17. Watson AW. Ankle sprains in players of the fieldgames Gaelic football and hurling. J Sports Med Phys Fitness 1999;39:66-70.

18. Fong DT, Hong Y, Chan LK, et al. A systematic review on ankle injury and ankle sprain in sports. Sports Med 2007:37:73-94.

19. Ekstrand J, Timpka T, Hägglund M. Risk of injury in elite football played on artificial turf versus natural grass: a prospective two-cohort study. Br J Sports Med 2006:40:975-80.

20. Orchard JW, Powell JW. Risk of knee and ankle sprains under various weather conditions in American football. Med Sci Sports Exerc 2003;35:1118-23.

21. Anderson KM. Movement control and cortical activation in functional ankle instability University of Minnesota; PhD thesis, ISBN: 9780549687610 , 2008.

22. Kofotolis $\mathbf{N}$, Kellis E. Ankle sprain injuries: a 2-year prospective cohort study in female Greek professional basketball players. J Ath/ Train 2007;42:388-94.

23. Kofotolis ND, Kellis E, Vlachopoulos SP. Ankle sprain injuries and risk factors in amateur soccer players during a 2-year period. Am J Sports Med 2007:35:458-66.

24. Bahr R, Bahr IA. Incidence of acute volleyball injuries: a prospective cohort study of injury mechanisms and risk factors. Scand J Med Sci Sports 1997; 7:166-71.

25. Verhagen EA, Van der Beek AJ, Bouter LM, et al. A one season prospective cohort study of volleyball injuries. Br J Sports Med 2004;38:477-81.

26. van Rijn RM, van Os AG, Bernsen RM, et al. What is the clinical course of acute ankle sprains? A systematic literature review. Am J Med 2008;121:324-31.e6.

27. Linde F, Hvass I, Jürgensen U, et al. Early mobilizing treatment in lateral ankle sprains. Course and risk factors for chronic painful or function-limiting ankle. Scand J Rehabil Med 1986:18:17-21. 
28. Hubbard TJ. Ligament laxity following inversion injury with and without chronic ankle instability. Foot Ankle Int 2008;29:305-11.

29. de Bie RA, de Vet $H C$, van den Wildenberg FA, et al. The prognosis of ankle sprains. Int J Sports Med 1997; 18:285-9.

30. Bachmann LM, Kolb E, Koller MT, et al. Accuracy of Ottawa ankle rules to exclude fractures of the ankle and mid-foot: systematic review. BMJ 2003;326:417.

31. Markert RJ, Walley ME, Guttman TG, et al. A pooled analysis of the Ottawa ankle rules used on adults in the ED. Am J Emerg Med 1998;16:564-7.

32. Myers A, Canty K, Nelson T. Are the Ottawa ankle rules helpful in ruling out the need for $\mathrm{x}$ ray examination in children? Arch Dis Child 2005;90:1309-11.

33. Perry JJ, Stiell IG. Impact of clinical decision rules on clinical care of traumatic injuries to the foot and ankle, knee, cervical spine, and head. Injury 2006:37:1157-65.

34. Pijnenburg AC, Glas AS, De Roos MA, et al. Radiography in acute ankle injuries: the Ottawa Ankle Rules versus local diagnostic decision rules. Ann Emerg Med 2002:39:599-604.

35. van Dijk CN, Lim LS, Bossuyt PM, et al. Physical examination is sufficient for the diagnosis of sprained ankles. J Bone Joint Surg Br 1996; 78:958-62.

36. van Dijk CN, Mol BW, Lim LS, et al. Diagnosis of ligament rupture of the ankle joint. Physical examination, arthrography, stress radiography and sonography compared in 160 patients after inversion trauma. Acta Orthop Scand 1996;67:566-70.

37. Brostroem L, Liljedahl SO, Lindvall N. Sprained ankles. II. arthrographic diagnosis of recent ligament ruptures. Acta Chir Scand 1965;129:485-99.

38. Mayer F, Herberger U, Reuber $\mathrm{H}$, et al. (Comparison of the value of held images and arthrography of the proximal ankle joint in injuries of the lateral capsule ligament system). Unfallchirurg 1987:90:86-91.

39. van Dijk CN, Molenaar $\mathrm{AH}$, Cohen $\mathrm{RH}$, et al. Value of arthrography after supination trauma of the ankle. Skeletal Radiol 1998;27:256-61.

40. Bleakley C, McDonough S, MacAuley D. The use of ice in the treatment of acute soft-tissue injury: a systematic review of randomized controlled trials. Am J Sports Med 2004;32:251-61.

41. Coté DJ, Prentice WE Jr, Hooker DN, et al. Comparison of three treatment procedures for minimizing ankle sprain swelling. Phys Ther 1988:68:1064-76.

42. Airaksinen 0, Kolari PJ, Miettinen H. Elastic bandages and intermittent pneumatic compression for treatment of acute ankle sprains. Arch Phys Med Rehabil 1990;71:380-3

43. Rucinkski TJ, Hooker DN, Prentice WE, et al. The effects of intermittent compression on edema in postacute ankle sprains. J Orthop Sports Phys Ther 1991;14:65-9

44. Tsang KK, Hertel J, Denegar CR. Volume Decreases After Elevation and Intermittent Compression of Postacute Ankle Sprains Are Negated by GravityDependent Positioning. J Athl Train 2003;38:320-4.

45. Bleakley CM, McDonough SM, MacAuley DC, et al. Cryotherapy for acute ankle sprains: a randomised controlled study of two different icing protocols. Br J Sports Med 2006;40:700-5; discussion 705

46. Kerkhoffs GM, Rowe BH, Assendelft WJ, et al. Immobilisation and functional treatment for acute lateral ankle ligament injuries in adults. Cochrane Database Syst Rev 2002;3:CD003762.

47. Lamb SE, Marsh JL, Hutton JL, et al. Mechanical supports for acute, severe ankle sprain: a pragmatic multicentre, randomised controlled trial. Lancet 2009:373:575-81.

48. Kerkhoffs GM, Struijs PA, Marti RK, et al. Different functional treatment strategies for acute lateral ankle ligament injuries in adults. Cochrane Database Syst Rev 2002; 3:CD002938.

49. Bleakley CM, O'Connor SR, Tully MA, et al. Effect of accelerated rehabilitation on function after ankle sprain: randomised controlled trial. BMJ 2010;340:c1964

50. van Rijn RM, van Os AG, Kleinrensink GJ, et al. Supervised exercises for adults with acute lateral ankle sprain: a randomised controlled trial. Br J Gen Pract 2007:57:793-800.

51. van Rijn RM, van Heest JA, van der Wees P, et al. Some benefit from physiotherapy intervention in the subgroup of patients with severe ankle sprain as determined by the ankle function score: a randomised trial. Aust J Physiother 2009;55:107-13.

52. Bleakley CM, McDonough SM, MacAuley DC. Some conservative strategies are effective when added to controlled mobilisation with external support after acute ankle sprain: a systematic review. Aust $J$ Physiother 2008;54:7-20

53. Brantingham JW, Globe G, Pollard $\mathrm{H}$, et al. Manipulative therapy for lower extremity conditions: expansion of literature review. J Manipulative Physiol Ther 2009;32:53-71.

54. Van der Wees PhJ, Lenssen AF, Hendriks HJM et al. Effectiveness of exercise therapy and manual mobilisation in acute ankle sprain and functional instability: a systematic review. Aust J Physiother 2006;52:27-37.

55. van Os AG, Bierma-Zeinstra SM, Verhagen $A P$, et al. Comparison of conventional treatment and supervised rehabilitation for treatment of acute lateral ankle sprains: a systematic review of the literature. J Orthop Sports Phys Ther 2005:35:95-105.

56. de Bie RA, de Vet HC, Lenssen TF, et al. Low-level laser therapy in ankle sprains: a randomized clinical trial. Arch Phys Med Rehabil 1998;79:1415-20.

57. Health Council of the Netherlands: Effectiveness of physical therapy; electrotherapy, laser therapy, ultrasound therapy. The Hague: Health Council of the Netherlands, 1999. http://www.gezondheidsraad.nl/ sites/default/files/99@20N.PDF

58. Mendel FC, Dolan MG, Fish DR, et al. Effect of high-voltage pulsed current on recovery after grades I and II lateral ankle sprains. J Sport Rehabil 2010;19:399-410.

59. Van den Bekerom MPJ, Van Der Windt DA Van Der Heijden GJ, et al. Ultrasound therapy for acute ankle sprains. Cochrane Database Syst Rev 2011:6:CD001250.

60. Barker AT, Barlow PS, Porter J, et al. A double-blind clinical trial of lower power pulsed shortwave therapy in the treatment of a soft tissue injury. Phys Ther 1985; 71:500-4.

61. Michlovitz SL, Smith W, Watkins M. Ice and high voltage pulsed stimulation in treatment of acute lateral ankle sprains* . J Orthop Sports Phys Ther 1988;9:301-4.

62. Pasila M, Visuri T, Sundholm A. Pulsating shortwave diathermy: value in treatment of recent ankle and foot sprains. Arch Phys Med Rehabil 1978;59:383-6.

63. Pennington GM, Danley DL, Sumko MH, et al. Pulsed, non-thermal, high-frequency electromagnetic energy (DIAPULSE) in the treatment of grade I and grade II ankle sprains. Mil Med 1993;158:101-4.

64. Wilson DH. Treatment of soft-tissue injuries by pulsed electrical energy. Br Med J 1972;2:269-70.

65. Kerkhoffs GMMJ, Handoll HHG, de Bie R et al. Surgical versus conservative treatment for acute injuries of the lateral ligament complex of the ankle in adults. Cochrane Database Syst Rev 2007:18:CD000380.

66. Hupperets MD, Verhagen EA, Heymans MW, et al. Potential savings of a program to prevent ankle sprain recurrence: economic evaluation of a randomized controlled trial. Am J Sports Med 2010;38:2194-200.

67. Cumps $\mathbf{E}$, Verhagen E, Meeusen R. Efficacy of a sports specific training programme on the incidence of ankle sprains in basketball. J Sports Sci Med 2007;6:212-19.

68. McGuine TA, Greene JJ, Best T, et al. Balance as a predictor of ankle injuries in high school basketbal players. Clin J Sport Med 2000:10:239-44.

69. Emery CA, Cassidy JD, Klassen TP, et al. Effectiveness of a home-based balance-training program in reducing sports-related injuries among healthy adolescents: a cluster randomized controlled trial. CMAJ 2005;172:749-54.

70. Handoll HHG, Rowe BH, Ouinn KM, et al. Interventions for preventing ankle ligament injuries. Cochrane Database Syst Rev 2001:3:CD000018.

71. Moiler K, Hall T, Robinson K. The role of fibular tape in the prevention of ankle injury in basketball: A pilot study. J Orthop Sports Phys Ther 2006;36:661-8.

72. Mickel TJ, Bottoni CR, Tsuji G, et al. Prophylactic bracing versus taping for the prevention of ankle sprains in high school athletes: a prospective, randomized trial. J Foot Ankle Surg 2006;45:360-5.

73. Curtis CK, Laudner KG, McLoda TA, et al. The role of shoe design in ankle sprain rates among collegiate basketball players. J Athl Train 2008;43:230-3.

74. Work Loss Data Institute. Ankle \& Foot lacute \& chronic), Corpus Christi (TX): Work Loss Data Institute, National Guideline Clearinghouse 2008:152.

75. Abidi NA. Sprains about the foot and ankle encountered in the workmans' compensation patient. Foot Ankle Clin 2002:7:305-22.

76. Kunkel M, Miller SD. Return to work after foot and ankle injury. Foot Ankle Clin 2002;7:421-8, viii.

77. Vriend I, van Kampen B, Schmikli S, et al. Ongevallen en bewegen in Nederland 2006-2007. Ongevalsletsels en sportblessures in kaart gebracht. Amsterdam: Stichting Consument en Veiligheid 2009

78. Bullock-Saxton JE, Janda V, Bullock ML The influence of ankle sprain injury on muscle activation during hip extension. Int J Sports Med 1994;15:330-4.

79. Wilkerson GB, Nitz AJ. Dynamic ankle instability: mechanical and neuromuscular interrelationships. J Sport Rehab 1994;3:43-57.

80. Eils $\mathbf{E}$, Rosenbaum D. A multi-station proprioceptive exercise program in patients with ankle instability. Med Sci Sports Exerc 2001;33:1991-8.

81. Lynch SA, Eklund U, Gottlieb D, et al. Electromyographic latency changes in the ankle musculature during inversion moments. Am J Sports Med 1996;24:362-9.

82. Vaes $\mathbf{P}$, Van Gheluwe B, Duquet W. Control of acceleration during sudden ankle supination in people with unstable ankles. J Orthop Sports Phys Ther 2001;31:741-52

83. van Cingel RE, Kleinrensink G, Uitterlinden EJ, et al. Repeated ankle sprains and delayed neuromuscular response: acceleration time parameters. J Orthop Sports Phys Ther 2006;36:72-9.

84. Hartsell HD, Spaulding SJ. Eccentric/concentric ratios at selected velocities for the invertor and evertor muscles of the chronically unstable ankle. Br J Sports Med 1999:33:255-8.

85. Hubbard TJ, Kramer LC, Denegar CR, et al. Contributing factors to chronic ankle instability. Foot Ankle Int 2007;28:343-54.

86. Santos MJ, Liu W. Possible factors related to functional ankle instability. J Orthop Sports Phys Ther 2008;38:150-7.

87. Tropp H. Pronator muscle weakness in functional instability of the ankle joint. Int J Sports Med 1986; 7:291-4

88. Wilkerson GB, Pinerola JJ, Caturano RW. Inverto vs. evertor peak torque and power deficiencies associated with lateral ankle ligament injury. J Orthop Sports Phys Ther 1997:26:78-86.

89. Burls A. AGREE I-improving the quality of clinical care. Lancet 2010;376:1128-9. 